\title{
Imagens do absoluto: o simbolismo religioso na poesia de Cecília Meireles
}

\section{Images of the absolute: the religious symbolism in the poetry of Cecília Meireles}

\author{
Rosana Rodrigues da Silva*
}

Resumo: Neste trabalho, analisamos os símbolos que expressam a religiosidade mística e oriental da autora Cecília Meireles, em Mar absoluto, tendo como suporte teórico a crítica da antropologia do imaginário e o estudo do simbolismo marítimo. O Mar figura um mundo de essência e de Unidade, portanto, de manifestação divina que se revela na obra da poeta.

Palavras-chave: Mar. Religião. Misticismo. Eu lírico.

Abstract: In this work, we analyze the symbols that express the mystique and eastern religiosity of the author Cecília Meireles, in Mar Absoluto, having as theoretical support the critical one of the anthropology of imaginary and the study of the maritime symbolism. The Sea appears a world of essence and Unit, therefore, of divine manifestation that if discloses in the workmanship of the poet. Key words: Sea. Religion. Mysticism. I Lyric .

Deixa-te estar embalado no mar noturno Onde se apaga e acende a salvação.

(Cecília Meireles)

Ao se buscar estudos críticos que têm se ocupado da obra poética de Cecília Meireles (1901-1964), pouco se vê publicado acerca da religiosidade em sua obra. Nesse ponto da discussão, a crítica se limita a analisar a influência espiritualista do grupo carioca de Festa, grupo de herança simbolista formado por Tasso da Silveira e Andrade Muricy. Partindo dessa relação, justificam as imagens vagas e o sentido de uma religiosidade difusa presente em toda produção da poeta

Da primeira publicação, Baladas para El-Rei (1925) até a segunda, Viagem (1939), não encontramos evolução no tema ou na forma para outro tipo

\footnotetext{
*Doutora em Literatura Brasileira pela UNESP (campus de São José do Rio Preto); professora do Departamento de Letras da UNEMAT (campus de Sinop). rosanrodrigue@ig.com.br
} 
de expressão. A autora simplesmente vai ampliando seu universo temático, tendo como referente a perscrutação do invisível e a mesma religiosidade que marcou suas obras iniciais.

De fato, o convívio com o grupo de Tasso da Silveira marcou a influência simbolista, delineando a feição espiritualista na obra ceciliana; mas também marcou o desinteresse da escritora pelas ações modernistas de vanguarda. A poeta foi pouco modernista, no que tange às inovações vanguardistas ou à irreverência paródica. Cecília Meireles recusou a dança no "ritmo dissoluto" e não se empolgou com o apelo "abaixo aos puristas". Sua modernidade foi muito mais filosófica do que estética, conforme notou a crítica. Sua lírica destaca-se no Modernismo brasileiro pela tendência a desvelar a NATUREZA, por fazer da intuição o seu guia nos caminhos do desconhecido.

Ao analisar a poesia ceciliana, torna-se impossível não reconhecer, ao lado do sentimento de exílio, a ânsia de libertação do mundo terreno rumo ao transcendente. A busca pelo ABSOLUTO, por meio de uma atitude contemplativa e estudiosa do universo, denuncia a visão religiosa da autora. Seu misticismo, portanto, está presente tanto nos momentos em que é tematizado (flos sanctorum, oratórios, cânticos), quanto na forma como a artista faz da sua poesia reflexão sobre a existência. A poeta revela em seus textos líricos uma força superior que a todos une e a crença de uma vida espiritual permitida pós-morte.

Com Mar absoluto (1945), Cecília Meireles atinge o símbolo maior de sua temática, pela "extinção da precariedade", pelo "toque divinatório" e pela "integração no Absoluto”. (AYALA, 1965, p. 26).

A matéria poética de Mar absoluto é formada pelo simbolismo marítimo que cerca o universo de um sujeito lírico perscrutador de um mundo de essências, na busca de um significado para a realidade que há por trás de um universo aparente.

Não é este mar que reboa nas minhas vidraças, mas outro, que se parece com ele como se parecem os vultos dos sonhos dormidos.

E entre água e estrela estudo a solidão

E recordo minha herança de cordas e âncoras, e encontro tudo sobre-humano.

E este mar visível levanta para mim 
uma face espantosa.

E retrai-se, ao dizer-me o que preciso.

E é logo uma pequena concha fervilhante, nódoa líquida e instável, célula azul sumindo-se no reino de um outro mar: ah! Do Mar Absoluto.

$(\text { Mar absoluto })^{1}$

O mar majestoso do mundo físico, admirado no ir e vir de suas ondas, não é descrito em sua aparência. A imagem do mar, arquétipo de criação, é escolhida para diferenciar dois mundos: o do Absoluto e o do Relativo, o da Essência e o da Aparência.

A recorrência às imagens do mar como matéria poética na obra ceciliana pode ser explicada pela influência da avó materna. Cecília Meireles foi educada por essa avó de origem insular, da ilha São Miguel (Açores), o que lhe possibilitou incorporar a linguagem náutica à sua lírica, formando uma “constelação de símbolos aquáticos”. (MELLO, 1994, p. 35-36).

A autora expressa em sua cosmovisão uma crença baseada no Oriente. A imagem de Deus estende-se por símbolos de infinitude que compreendem a experiência religiosa e afetiva da artista. Sua religiosidade se traduz no autoentendimento, na descoberta ou construção do Si mesmo.

Contrariamente à poética de seus contemporâneos, Murilo Mendes e Jorge de Lima, a poesia de Cecília Meireles não apresenta a angústia do pecador. As imagens de Mar absoluto revelam a presença de um Deus transfigurado em símbolos de infinitude, sentidos na extensão da natureza.

Da consciência da ineficácia dos poderes de um Deus único origina o misticismo da poeta que tende a buscar na natureza e em seus grandes arquétipos as respostas para suas preocupações filosóficas: "E que deus me dará força tão poderosa/ para assim resistir toda a vida desperta/ e com os deuses conter a tempestade certa?” (Vigilância) ${ }^{2}$.

A indagação do sujeito lírico revela a perturbação de um ser confuso diante dos mistérios que não compreende e de um Deus que não reconhece

\footnotetext{
${ }^{1}$ MEIRELES, C. Mar Absoluto e outros poemas. Poesia completa. Rio de Janeiro: Nova Aguilar, 1994.

${ }^{2}$ Idem, ibidem.
} 
como o Todo-Poderoso. Na busca de uma resposta, o sujeito poético adquire nos textos a forma transcendente, revelando uma concepção oriental no modo como busca entender os mistérios divinos.

Jung, em Psicologia e religião oriental (1989), distingue duas concepções religiosas que marcam o imaginário humano. Se, para o Ocidente cristão, o homem depende da graça de Deus ou da Igreja; para os orientais, o homem deve ser o único meio eficaz de sua própria evolução superior. O homem ocidental reconhece-se infinitamente pequeno perto da graça de Deus; já o homem oriental busca na evolução de seu espírito a graça divina.

Deus não é visto no Oriente como um ser acrescentado ao mundo que o homem conhece. A divindade apenas pode ser revelada ao religioso oriental através de uma experiência que não pode ser expressa por palavras ou conceitos. Assim, a experiência mística torna-se a única prova digna de confiança.

Nos poemas de Cecília Meireles, a experiência se dá pela atitude lírica de um sujeito que evolui na busca de sua espiritualidade.

Venho de caminhar por estas ruas.

Tristeza e mágoa. Mágoa e tristeza.

Tenho vergonha dos meus sonhos de beleza.

Caminham sombras duas a duas,

felizes só de serem infelizes,

e sem dizerem, boca minha, o que tu dizes...

De não saberem, simples e nuas,

coisas da alma e do pensamento, e que tudo foi pó e que tudo é do vento...

Felizes com as misérias suas, como eu não poderia ser com a glória, porque tenho intuições, porque tenho memória...

Porque abraçada nos braços meus, porque, obediente à minha solidão,

vivo construindo apenas Deus...

(Transeunte)

\footnotetext{
${ }^{3}$ Idem, ibidem. 
A construção de Deus remete à construção do sujeito lírico. Sua formação deve-se à sua caminhada pelo mundo que o faz amadurecer por meio de provações, tornando-o um ser espiritualizado que recusa os "sonhos de beleza" de um mundo sedutor. As intuições e memórias de outras vidas auxiliam-no em sua experiência mística. Intuitivo, o sujeito poético mostra um Deus construído dentro de si mesmo.

Desse modo, Deus não surge como foi concebido pela tradição judaicocristã, mas como presença divina que se estende à natureza. No mundo natural, a poeta busca a contemplação divina. Integrando-se a ele, aproxima-se de Deus. No budismo, como na visão pagã, os deuses, a natureza e a humanidade estão unidos em simpatia. (Cf. ARMSTRONG, 2001, p. 43-44).

O mar é a natureza escolhida para o sentimento da divindade. Em todos os seus livros, Cecília expressou as diversas atitudes de sua passagem pelo mar, símbolo que determina, para ela, a "integração no Absoluto". (AYALA, 1965, p. 34-35). O simbolismo divino do mar encontra justificativa em sua expressão da eternidade, daquilo que não possui começo e nem fim.

A figura do mar sempre foi bastante almejada pelos poetas. O mar fascina por ser, ao mesmo tempo, uma imensidade multiplicada, una e eterna, com a aparência imóvel do instante. Sua superfície funciona como um espelho que "duplica a profundidade ascendente do céu e incorpora os elementos da alteridade superior"; por isso o mar possui uma magnitude, cujo significado poderá ser a “forma metafórica do infinito e do inefável”. (PRADO, 1993, p. 340-341).

O mar majestoso é constantemente recuperado pela autora que o torna síntese de sua consciência criadora e metáfora do Absoluto que nunca se extingue e que pode proporcionar aos seres a espiritualidade.

O significado de regeneração espiritual das águas presentifica-se no ritual do batismo e estende-se às tradições de dilúvios que vinculam a ideia de uma reabsorção da humanidade na água à instauração de uma nova era. (ELIADE, 1974, p. 230).

O mar contemplado, antes de tudo, é água, "água de todas as possibilidades”, onde o sujeito lírico irá buscar sua evolução. Esse mar basta por si mesmo e modifica-se para o contínuo de sua eternidade. 
O abismo marinho converte-se em grandiosidade que seduz:

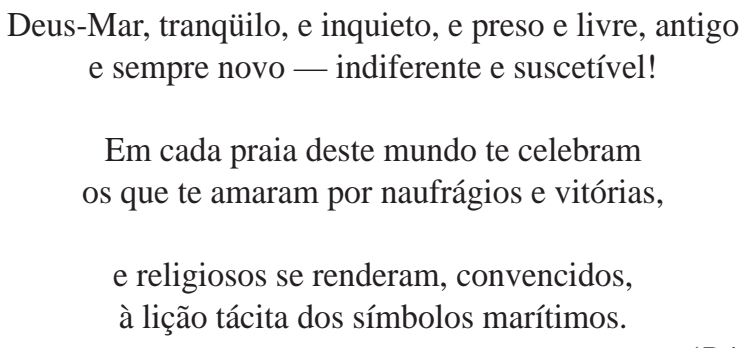

O Deus-Mar mostra-se contraditório em si mesmo; tranquilo e inquieto, preso e livre, antigo e novo, indiferente e suscetível; mas é sempre celebrado por suas lições tácitas. Os povos se rendem aos ensinamentos de seus símbolos marítimos. Seu dom profético, de grande oráculo, traz as respostas às indagações humanas. Com isso, a poeta retoma a simbologia do poder profético que emana das águas, presente desde a Antiguidade que já via o oceano como uma "casa da sabedoria". (ELIADE, 1974, p. 236).

A julgar pelas imagens evocadas de um Mar divino, é possível reconhecer um sentimento místico de Deus: "que é da presença passageira e esquiva/ das heranças dos poetas, malogradas:/ a estrela, o passarinho, a sensitiva,/ a água que nunca volta, a bem-amada,/ a saudade de Deus, vaga e inativa ...?” (Museu) $)^{5}$.

No questionamento das coisas que se perderam, a poeta inclui a saudade de Deus, mas “vaga e inativa”. A saudade dita desse modo não constitui um sentimento de ausência, mas apenas a negação da existência desse Deus, resumida na breve lembrança do que um dia pôde existir. A vagueza e a inatividade não qualificam o Deus que a poeta distingue, mas sim a saudade perdida.

A figura de Deus, como ordenador do mundo, não é sentida de modo positivo; ao contrário, está associada à condenação, à infelicidade de um destino malogrado. O Deus que acalma e ensina está presente nos símbolos marítimos e relaciona-se à crença espiritualista e oriental.

\footnotetext{
${ }^{4}$ Idem, ibidem.

${ }^{5}$ Idem, ibidem. 
A oposição entre mundo terreno e mundo divino é marcada pelo estranhamento do sujeito lírico: "Quem me deseja ouvir netas paragens/ onde todos somos estrangeiros?” (Contemplação) ${ }^{6}$.

Na forma de um ser espiritual, o eu poético revela-se perdido no mundo terreno. Por isso seu percurso será sempre ascendente, em um movimento que revela o caminho da mística. A poeta cria a figura de um sujeito que se apresenta nos poemas como alma solitária. O significado religioso da alma, de acordo com o estudo de Balakian (1969), corresponde à consciência da psique universal do homem perdido em um mundo físico.

A poeta estranha o mundo dos homens e sente-se compromissada com outras vidas. Para responder ao próprio destino, é necessário se apresentar como um ser instruído pela mística:

Esta sou eu — a inúmera.

Que tem de ser pagã como as árvores

E, como um druida, mística.

Com a vocação do mar, e com seus símbolos.

Com o entendimento tácito, instintivo,

das raízes, das nuvens, dos bichos e dos arroios caminheiros.

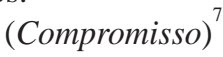

O compromisso do sujeito poético está em seguir uma vocação mística e, por meio dela, compreender tacitamente e instintivamente os desígnios da natureza, dos mais uterinos, como as raízes, aos mais etéreos, como as nuvens. Para isso, deve ser pagã como as árvores que representam a síntese da natureza e da vida. A poeta, desse modo, ignora a fé cristã para praticar seu misticismo, compondo a figura mística do sujeito lírico alia-se à imagem do poeta sofredor, encarregado de suportar nos ombros o peso do mundo.

O sentimento nostálgico do porvir, o "infinito anelo" que Bosi (1989) reconhece nos românticos, define as imagens do infinito, da eternidade e do horizonte, espaço por onde excursiona o eu poético.

\footnotetext{
Idem, ibidem.

${ }^{7}$ Idem, ibidem. 
O modo como se compreende no mundo faz esse sujeito questionar sua existência:

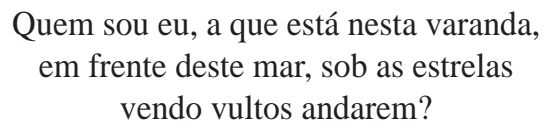

(Distância) $^{8}$

Pergunto a Deus se estou viva, se estou sonhando ou acordada. Lábio de Deus! - Sensitiva

Tocada.

$(\text { Noite })^{9}$

As questões evocadas na obra ceciliana demonstram a figura de um eu poético preocupado com temas metafísicos, e que se lança à reflexão com o objetivo de compreender o mundo, a vida humana e, sobretudo, a verdadeira essência das coisas. Daí o sentido de uma poesia, como nota Afrânio Coutinho, “(...) densa, pensada e sofrida a um tempo”. (1970, p. 117).

O poeta religioso ou de experiência religiosa, intencionalmente ou não, prega sua crença e aconselha a humanidade. Com isso, ele mesmo é um testemunho de fé; por isso necessita dizer, alertar aqueles que foram julgados surdos e cegos diante dos mistérios divinos.

Fascinação e temor são duas atitudes que marcam a reação da humanidade diante da visão do sagrado. Nela, tem-se um profundo choque que vem do medo e, paradoxalmente, de uma atração irresistível. O profeta Isaías, na bíblia judaico-cristã, experimentou a sensação do numinoso que baixava sobre os homens escolhidos. Isaías, dominado pela santidade transcendente de Javé, tinha consciência de sua impureza e sofria com a visão divina. Esse profeta não era nenhum Buda experimentando a iluminação que trazia tranquilidade e felicidade, ao contrário, estava tomado de terror mortal. (Cf. ARMSTRONG, 2001, p. 52). Seu contato com Deus lhe vem como uma graça que aterroriza e fascina.

\footnotetext{
${ }^{8}$ Idem, ibidem.

${ }^{9}$ Idem, ibidem. 
A busca da graça divina, por meio de um exercício duro da virtude ou da reflexão que leva à virtude, é a que melhor define o caminho de acesso à divindade na poesia de Cecília Meireles. Nesse acesso direto, a graça alcançada iguala-se a um exercício também de libertação humana.

Do mesmo modo que Buda necessitou preparar-se a fim de alcançar a iluminação, certos poetas religiosos buscam a visão do sagrado por meio de exercícios ritualísticos ou de reflexão. As verdades últimas, a ideia de Deus, são captadas intuitivamente por meio das disciplinas mentais da meditação.

Na poesia ceciliana, o eu poético conhece as ilusões de um mundo passageiro, por isso sente a necessidade de realizar um exercício de reflexão no espaço contemplado de seu poema, a fim de que lhe seja possível reconhecer a verdade que há por trás das coisas aparentes:

É preciso que exista, enfim, uma hora clara, depois que os corpos se resignam sob as pedras como máscaras metidas no chão.

Por entre as raízes, talvez se veja, de olhos fechados, Como nunca se pôde ver, em pleno mundo,

Cegos que andamos de iluminação.

$$
{\text { (Futuro })^{10}}^{10}
$$

A iluminação deve vir no momento de hora clara, após o repouso dos corpos sobre a pedra. A luz e a pedra, símbolos de ascensão e presença divina, possibilitam ao sujeito lírico, de olhos fechados, alcançar a verdade. O exercício espiritual, em que se tem maior contato com Deus, será também o momento de reconhecer e discernir coisas inúteis e frágeis do eterno e verdadeiro. Na busca do encontro místico, a poeta se constrói; adquire sua consciência de ser iluminado na reflexão revelada no poema.

Em toda a obra Mar absoluto, é reconhecível o exercício de sondagem filosófica que auxilia numa ascese espiritual. Poemas como "Contemplação", "Compromisso", "Sugestão" e os chamados "Motivos da Rosa” propõem de modo reflexivo uma meditação sobre os valores da vida e da morte empreendendo uma viagem de autoconhecimento:

\footnotetext{
${ }^{10}$ Idem, ibidem. 
Rosana Rodrigues da Silva

Então, é comigo que falam, sou eu que devo ir.

Porque não há mais ninguém, não, não haverá mais ninguém , tão decidido a amar e a obedecer a seus mortos.

$$
\text { (...) }
$$

Para adiante! Pelo mar largo!

Livrando o corpo da lição frágil da areia!

Ao mar! - Disciplina humana para a empresa da vida!

(Mar Absoluto)

Opondo-se ao mar, está a areia, com sua "lição frágil”. O mar, “disciplina humana para empresa da vida”, torna-se o símbolo da aprendizagem; opõe-se à terra e à areia. Em função do mar, vão se definindo na obra instâncias metafóricas. De um poema a outro, a poeta constrói uma rede de temas e metáforas que organizam, por analogia ou por oposição, a cosmografia ceciliana em torno do simbolismo marítimo. Corais, pérolas, peixes, ondas, sereias, caramujo, marinheiro, conchas, o brumoso navio, a sonolenta vela, o barqueiro Caronte - todos esses elementos formam conteúdos de um Mar majestoso e continente.

Os poemas da obra revelam o semantismo do mar, transformado em um espaço onírico, nebuloso, no continente adequado para um universo mítico. O grande mar profundo e hermético seduz porque abriga o mistério. Na Oceania é muito frequente a crença de que os mortos acompanham o sol pelo oceano, navegando em barcas. (Cf. ELIADE, 1974, p.169). No reino do mar ABSOLUTO, o eu poético busca seus mortos e apreende a sua verdade. O mar metaforizado ascende da categoria mineral à animal ou vegetal:

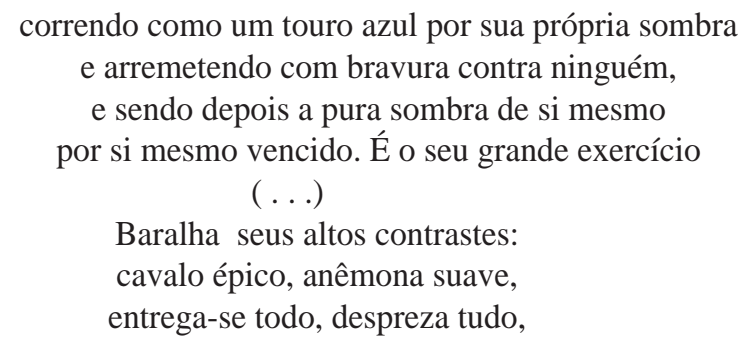

Baralha seus altos contrastes: cavalo épico, anêmona suave, entrega-se todo, despreza tudo,

\footnotetext{
${ }^{11}$ Idem, ibidem. 
Imagens do absoluto: o simbolismo religioso na poesia de Cecília Meireles

sustenta no seu próprio ritmo

jardins, estrelas, caudas, antenas, olhos, mas é desfolhado, cego, nu, dono apenas de si, da sua terminante grandeza despojada.

(Mar absoluto)

Como "touro azul”, como "cavalo épico" e "anêmona suave”, o mar torna-se ABSOLUTO. Entregando-se todo e desprezando tudo, o mar sustenta o ritmo circular da onda que se entrega e depois se recolhe. Nas formas que contém, o mar sustenta caudas, antenas e olhos daqueles seres que o habitam, bem como os jardins de seu reino vegetal. Também as estrelas são elementos desse grande mar que reflete o céu em sua superfície. Entretanto, o mar independe de todos os elementos que sustenta, pois existe sem eles. Assim é o mar "desfolhado, cego, nu”, senhor de sua própria grandeza.

E retrai-se, ao dizer-me o que preciso.

E é logo uma pequena concha fervilhante, nódoa, líquida e instável, célula azul sumindo-se no reino de um outro mar: ah! do Mar Absoluto.

(Mar absoluto)

A contemplação da metamorfose constante do mar grandioso em "pequena concha fervilhante” transporta o sujeito lírico para a compreensão de uma outra realidade, de um espaço espiritual e inefável do sujeito. No ir e vir das ondas, na imagem do mar que vence a si mesmo, compreende-se o grande exercício marítimo. A metáfora engrandecedora do mar fornece a magia de algo divino e sobrenatural. O Mar, “água de todas as possibilidades”, enquanto arquétipo da criação, forma o próprio eu poético.

Aceita-me apenas convertida em sua natureza:

plástica, fluida, disponível, igual a ele, em constante solilóquio, sem exigências de princípio e fim, desprendida de terra e céu.

$(\text { Mar absoluto })^{12}$

\footnotetext{
${ }^{12}$ Idem, ibidem.
} 
A descoberta de uma verdade superior ao ilusório e aparente mundo dos mortais realiza-se através do entendimento tácito do Mar.

A meditação e o recolhimento lírico na poesia ceciliana remontam à teoria platônica. Para encontrar a verdade sob a aparência do mundo real, a alma necessita remodelar-se; passar por um período de purificação e empenhar-se na atitude contemplativa. $\mathrm{O}$ indivíduo deve olhar além do mundo sensível e até mesmo além das limitações do intelecto.

$\mathrm{O}$ acesso indireto ao sagrado se faz, antes, por meio da alma. A presença de familiares já mortos e a visão de reencarnações são frequentes nos poemas de Mar absoluto: "À suave morta, que dizem os figurinos abertos/ e seu espelho e seu perfume e seus anéis?” (Suave morta) ${ }^{13}$.

A morte torna-se o caminho para que o homem se torne mais instruído. A figura do barqueiro Caronte, como condutor da alma, intensifica a relação do sujeito lírico com o reino dos mortos:

Caronte, juntos agora remaremos: eu com a música, tu com os remos.

Meus pais, meus avós, meus irmãos, já também vieram pelas tuas mãos.

Mas eu sempre fui a mais marinheira: trata-me como tua companheira.

Fala-me das coisas que estão por aqui, das águas, das névoas, dos peixes, de ti. Que mundo tão suave! Que barca tão calma! Meu corpo não viste: sou alma.

${\text { (Caronte })^{14}}^{14}$

A presença da barca condutora ao mundo dos mortos auxilia nessa função de busca pelo transcendente. A barca é símbolo da travessia realizada pelos mortos para o Além. (Cf. CHEVALIER, GHEERBRANT, 1995, p. 121). Assim, Caronte não é apenas o condutor, mas o elo de comunicação com esse suave mundo. A serenidade sentida no novo espaço deflagra o acolhimento

\footnotetext{
${ }^{13}$ Idem, ibidem.

${ }^{14}$ Idem, ibidem. 
através do qual o sujeito lírico sente a morte que chega. Embora Bachelard (apud CHEVALIER, GHEERBRANT, 1995, p. 122) tenha afirmado que a barca de Caronte vai apenas para os infernos, significando sempre um símbolo que permanecerá ligado à infelicidade dos homens, na poesia ceciliana a barca de Caronte é um berço benfazejo, "tão calmo", que desperta tranquilidade para o sujeito lírico, como se nota nos versos finais do poema. A ressignificação para o barqueiro Caronte se dá graças à inversão do simbolismo da morte. Como esclarece Durand, o eufemismo inverte os símbolos nictomórficos do regime diurno do imaginário humano. A morte, na poesia ceciliana, não significa um fim em si, mas o recomeço de uma outra etapa em um espaço liberto das aflições humanas. A mudança do corpo marca a transposição de mundos efetuada pelo eu lírico em forma de alma.

É dado à alma humana saber mais do que o limitado e finito corpo. Esse apenas sabe de sua existência, mas é a alma que tudo sabe e conhece inclusive os mistérios que rodeiam o espaço entre o nascimento e a morte, conforme expressou Cecília Meireles: "As palavras aí estão, uma por uma:/ porém minha alma sabe mais”. (Interpretação) ${ }^{15}$.

A alma guia solitária o eu poético, configurando-se na presença de um ser leve que anima e direciona a matéria no mundo, seguramente, como uma bússola em sua vida. Assim divina, a alma é portadora das respostas que cercam os mistérios da vida humana.

Através da concepção que empresta à alma maiores poderes e maior sapiência do que ao corpo físico, a poeta retoma a teoria platônica das ideias. O sentido religioso dessa teoria está em mostrar que o processo cognoscitivo é apresentado como força de ascensão que conduz à contemplação mística. (Cf. REALE, 1994, p. 45). Segundo Platão, as coisas captadas com os olhos do corpo são formas físicas; as coisas captadas com o olho da alma são formas não-físicas. O ver da inteligência capta formas inteligíveis que são essências puras. As ideias são as essências eternas do bem, do verdadeiro, do belo, do justo que a inteligência consegue fixar ou ver. (Cf. REALE, 1994, p. 63). A contemplação das ideias é alcançada pelo eu poético ceciliano que compreende o mundo do inteligível que transcende a matéria sensível.

As almas dos homens, criadas por um Deus demiurgo, são a dimensão inteligível e imaterial do homem, capazes de alcançar a contemplação das

\footnotetext{
${ }^{15}$ Idem, ibidem. 
ideias. No entanto, quando se apoiam sobre as percepções sensíveis, as almas erram e confundem-se; somente quando a alma se eleva sobre os sentidos e se recolhe para não errar mais, consegue encontrar nas idéias puras e no Inteligível o seu objeto adequado; descobre ser thes afim e, pensando as coisas imutáveis permanece imutável. (REALE,1994, p. 186).

Em Mar absoluto, a maternidade da Terra e das Águas revela um universo feminino que a autora busca retratar como superior a um masculino. As imagens de uma natureza maternal e protetora transportam o sujeito lírico para um mundo eufêmico. Conforme lembra Durand (1997, p. 233), o eterno feminino e sentimento da natureza "caminham lado a lado em literatura".

A presença da avó materna e de uma natureza acolhedora transmitem a visão de um universo de volúpia, felicidade e sabedoria, consagradas como essência do universo poético feminino:

E minha avó cantava e cosia. Cantava canções de mar e de arvoredo, em língua antiga.

E eu sempre acreditei que havia música em seus dedos e palavras de amor em minha roupa escritas

Minha vida começa num vergel colorido, por onde as noites eram só de luar e estrelas.

Levai-me aonde quiserdes! - aprendi com as primaveras a deixar-me cortar e a voltar sempre inteira.

$$
(\text { Desenho })^{16}
$$

A lição tácita da natureza está na transposição dos obstáculos, com o fortalecimento do sujeito lírico que aprende a recompor-se após obras malogradas do destino. A contemplação da natureza propicia-lhe as grandes aprendizagens. Assim, sua reflexão realiza-se por meio de um tácito entendimento do mundo natural:

\footnotetext{
Não te aflijas com a pétala que voa: também é ser, deixar de ser assim. Rosas verás, só de cinza franzida, mortas intactas pelo teu jardim.

Eu digo aroma até nos meus espinhos,
}

\footnotetext{
${ }^{16}$ Idem, ibidem. 
Imagens do absoluto: o simbolismo religioso na poesia de Cecília Meireles

ao longe, o vento vai falando de mim.

E por perder-me é que me vão lembrando, por desfolhar-me é que não tenho fim.

$\left(4^{\circ} \text { Motivo da Rosa }\right)^{17}$

O universo feminino representado pelo sentimento da natureza faz o eu lírico desvendar na própria finitude a lógica da existência que há no mundo terreno. A imagem das rosas já mortas que permanecem no jardim trazem a epifania da vida. Assim como o "não ser" é, a morte não impede que as rosas continuem a existir. Logo, não é necessário afligir-se com nada; nem com os bens perdidos, pois há "aromas até nos espinhos".

É principalmente como aprendiz dos símbolos aquáticos que a poeta aceita a lição do universo feminino. A espiritualidade humana é buscada no mar, também visto como feminino e maternal, pois é arquétipo da descida e do retorno às fontes originais da felicidade. (Cf. DURAND, 1997, p. 225). Nele, a poeta encontra as potências necessárias à sua renovação:

Sou moradora das areias, de altas espumas: os navios passam pelas minhas janelas como o sangue nas minhas veias, como os peixinhos nos rios ...

Não têm velas e têm velas; e o mar tem e não tem sereias; e eu navego e estou parada, vejo mundos e estou cega, porque isto é mal de família, ser de areia, de água, de ilha ...

$E$ até sem barco navega quem para o mar foi fadada.

Deus te proteja, Cecília, Que tudo é mar - e mais nada.

$\left(\right.$ Beira-Mar) ${ }^{18}$

\footnotetext{
${ }^{7}$ Idem, ibidem.

${ }^{18}$ Idem, ibidem.
} 
As constantes imagens da água em Marabsoluto trazem à poeta a embriaguez do devaneio. De acordo com Bachelard (1988, p. 61), “[...] quem é marcado pela água guarda uma fidelidade à sua anima”, essência do feminino. Pode-se mesmo afirmar que a leitura da obra ceciliana deve ser realizada em anima. Esse tipo de leitura põe o leitor em um estado de devaneio, entregando-o à tranquilidade da descida para a profundeza do repouso, longe das preocupações, das ambições e dos projetos. (Cf. BACHELARD, 1988, p. 60-61). À anima pertencem as imagens serenas de uma contemplação desinteressada e afetuosa na poesia ceciliana.

A necessidade de ver-se protegido num espaço acolhedor, revelada no simbolismo maternal da Terra e do Mar, apresenta-se também no desejo de transcendência. A vontade de percorrer o céu e o infinito, de perseguir pássaros, de alcançar altas montanhas traz, para os poemas, os símbolos ascensionais. Enquanto o simbolismo marítimo é formado pelas imagens da água, da barca e dos peixes; o transcendente é reconhecido nos símbolos aéreos (nuvens, estrelas, céu, ar e pássaros).

Visões da maternidade e do transcendente auxiliam para a reflexão lírica. O pássaro que mergulha nas águas e voa no céu, imagem bastante recorrente na obra ceciliana, simboliza uma influência celeste e, ao mesmo tempo, uma aquática; assim como a chuva e o orvalho. A união do celeste e do aquático conquista, no trabalho poético com os símbolos, seu grau máximo de significação da divindade. A água (símbolo de criação), mergulhada pelo pássaro (influência celeste), torna-se mais divina. O universo maternal e o transcendente são próprios desse mundo.

Sobre os símbolos ascensionais, Durand (1997, p. 127) argumenta que esse simbolismo busca recuperar uma potência perdida pela queda. O simbolismo - da asa, das aves, da águia, do corvo, da pomba - constitui uma experiência imaginária dos elementos aéreos que rumam a um espaço metafísico, para além da materialidade do tempo.

Enriquecido pela transcendência, o eu poético será superior a si mesmo e aos outros seres. Assim, contrário a um universo masculino e dominador, busca divinizar-se e divinizar o mundo que contempla, mostrando-o de forma singular, mais maternal e mais feminina.

Como já foi possível afirmar em nosso trabalho de mestrado ${ }^{19}$, a poeta, com imagens recorrentes da criação e na quase ausência de arquétipos

\footnotetext{
${ }^{19}$ A contemplação em Viagem. Porto Alegre (UFRGS), 1997, 176p. Dissertação, (Mestrado em Literatura Brasileira). 
masculinos, manifesta sua recusa a temáticas do racionalismo, criando um canto liberto das circunstâncias da realidade opressora. Sua religiosidade não advém dos preceitos do catolicismo, ou do cristianismo ocidental, mas sim do misticismo oriental que marca as recorrências simbólicas e a visão do Absoluto em seus poemas.

\section{Referências}

ARMSTRONG, K. Uma história de Deus. (Quatro milênios de busca do judaísmo, cristianismo e islamismo). $4^{\mathrm{a}}$ ed. São Paulo: Companhia das Letras, 2001.

AYALA, W. Nas fronteiras do mar absoluto. In: Sebastiam... Rio de Janeiro: José Olympio, 1965.

Crônica trovada da cidade de Sam

BACHELARD, G. A poética do devaneio. São Paulo: Martins Fontes, 1988.

BALAKIAN, A . El Movimento Simbolista. Madrid: Ediciones Guadarrama, 1969.

BOSI, A. História concisa da literatura brasileira. São Paulo: Cultrix, 1989.

CHEVAliER, J. , GHEERBRANT, A . Dicionário de símbolos. Rio de Janeiro: José Olympio, 1995.

COUTINHO, A . A reação espiritualista. In: A literatura no Brasil. Rio de Janeiro: Sul Americana, 1970, v. IV, V .

DAMASCENO, D. Poesia do sensível e do imaginário. In: MEIRELES, C. Poesia completa. Rio de Janeiro: Nova Aguilar, 1994.

DURAND, G. As estruturas antropológicas do imaginário. São Paulo: Martins Fontes, 1997.S

ELIADE, M. Tratado de historia de las religiones. Madrid: Ediciones Cristiandad, 1974. Vol. I, II.

JUNG, C. G. Psicologia e religião oriental. Petrópolis: Vozes, 1989.

MEIRELES, C. Mar Absoluto e outros poemas. Poesia completa. Rio de Janeiro: Nova Aguilar, 1994.

MELLO, A. M. L. de. A linguagem náutica na poesia de Cecília Meireles. FAPA (Revista da Faculdade Porto-Alegrense de Educação, Ciências e Letras). Porto Alegre, no 14, p.3541, 1994.

PRADO, J. del. Teoría y prática de la función poética. Madrid: Edicions Cátedra, S. A, 1993.

REALE, G. História da filosofia antiga II (Platão e Aristóteles). Tradução de Henrique Cláudio de Lima Vaz e Marcelo Perine. São Paulo: Loyola, 1994. (Série História da Filosofia). 
SILVA, R. R. da. A contemplação em Viagem: um estudo do olhar na poesia de Cecília Meireles. Porto Alegre, 1997, 176p. Dissertação. (Mestrado em Literatura Brasileira) Universidade Federal do Rio Grande do Sul.

Recebido para publicação em 01 nov. 2009 Aceito para publicação em 01 dez. 2010 